\title{
Brain Cell Type Specificity and Gliosis-Induced Activation of the Human Cytomegalovirus Immediate-Early Promoter in Transgenic Mice
}

\author{
Jean-Marc Fritschy, ${ }^{2}$ Sebastian Brandner, ${ }^{3}$ Adriano Aguzzi, ${ }^{3}$ Marieke Koedood, ${ }^{1}$ Bernhard Lüscher, ${ }^{2}$ and \\ Pamela J. Mitchell ${ }^{1}$
}

Institutes of ${ }^{1}$ Molecular Biology and 2 Pharmacology, University of Zürich, $\mathrm{CH}-8057$ Zürich, Switzerland, and ${ }^{3 / n s t i t u t e}$ of Neuropathology, University Hospital, $\mathrm{CH}-8091$ Zürich, Switzerland

\begin{abstract}
Human cytomegalovirus (HCMV) can cause debilitating, sometimes fatal, opportunistic infections in congenitally infected infants and in immunodeficient individuals such as patients with the acquired immunodeficiency syndrome (AIDS). Molecular mechanisms that determine cell type specificity of HCMV infection and latency are poorly understood. We recently described a transgenic mouse model for analysis of HCMV major immediate-early (IE) promoter regulation and showed that sites of IE promoter activity during murine embryogenesis correlate with known target tissues of congenital HCMV infection in human fetuses (Koedood et al., 1995). Among various permissive human tissues, the brain is a site where HCMV infections can be devastating. Here, we have used immunohistochemical double-labeling analysis to identify specific cell types with HCMV-IE promoter activity in brains of transgenic mice at several postnatal stages. IE promoter activity was restricted to some endothelial cells, ependymal cells, choroid plexus epithelia, and neurons at discrete locations in the forebrain, brain-
\end{abstract}

stem, and cerebellum. Endothelial cells and neurons with activity were proportionately more abundant in neonatal than in adult brains. Although the IE promoter was normally silent in most astrocytes, activity was strongly induced in reactive astrocytes in response to a neocortical stab lesion. The findings support a model, consistent with clinical literature on HCMV encephalitis, whereby tissue damage and gliosis caused by HCMV infection of endothelial and ependymal cells progressively renders adjacent permissive neurons and reactive astrocytes accessible to infection. This transgenic model system should facilitate identification of factors that regulate the HCMV IE promoter with regard to infection permissivity and reactivation from latency.

Key words: HCMV major immediate-early promoter; brainspecific transcription; viral pathogenesis; encephalitis; congenital HCMV infection; AlDS; blood-brain barrier; astrocytes; gliosis
Human cytomegalovirus (HCMV), a common herpes virus, establishes permanent residence in the host after primary infection, and viral replication can be periodically reactivated (Alford and Britt, 1990). Although HCMV rarely causes symptomatic disease in healthy human hosts, when immune mechanisms to neutralize and clear virus from the bloodstream are impaired, opportunistic HCMV infections increase in virulence and persistence. HCMV can be potentially life-threatening in immunodeficient patients and congenitally infected fetuses and infants (Bale, 1984; Klatt and Shibata, 1988; Huang and Kowalik, 1993; Vinters and Ferreiro, 1993; Wiley and Nelson, 1993). Congenital HCMV infection is the most frequent cause of prenatal injury to the CNS and can result in mental retardation, para- and quadriplegia, spasticity, sensorineural hearing deficits, optic atrophy, and seizure disorders (Saigal et al., 1982; Bale, 1984; Perlman and Argyle, 1992). HCMV is frequently associated with morbidity and mortality in immunosuppressed bone marrow or organ transplantation pa-

\footnotetext{
Received Sept. 27, 1995; revised Dec. 20, 1995; accepted Jan. 5, 1996.

This study was supported by a Swiss National Science Foundation grant to P.J.M. (Nr. 31-30900.91). We thank Oliver Weinmann, Christina Torres-de los Reyes, and Annette Fichtel for technical assistance, and Dr. Hanns Mohler for interest and encouragement.

Correspondence should be addressed to Pamela J. Mitchell, Institute of Pharmacology, University of Zurich, Winterthurerstrasse 190, 8057 Zürich, Switzerland.

Dr. Koedood's present address: Department of Biology, 5 Cummington Street, Boston University, Boston, MA 02215.

Copyright (C) 1996 Society for Neuroscience $0270-6474 / 96 / 162275-08 \$ 05.00 / 0$
}

tients, cancer patients receiving chemotherapy, and patients with AIDS. HCMV is the most common opportunistic viral agent in AIDS patients and has the essential features of a cofactor in the progression from human immunodeficiency virus (HIV) infection to AIDS (Huang and Kowalik, 1993). HCMV infections of the CNS can cause necrotizing encephalitis and ependymitis and, in AIDS patients, can result in AIDS dementia complex complicated by cytomegalovirus encephalopathy, a syndrome distinguished by HCMV viremia, intra-blood-brain barrier HCMV antibody production, seizures, coma, and rapid demise (Fiala et al., 1993). Approximately half of AIDS patients show widespread HCMV infection at autopsy, with $>20 \%$ of these demonstrating CNS involvement (Klatt and Shibata, 1988). This frequency is similar to the $25 \%$ frequency of CNS involvement observed for preterm infants with lethal congenital HCMV infections (Perlman and Argyle, 1992).

Molecular mechanisms that determine cellular permissivity, reactivation, and progressive infection by ICMV are poorly defined. Cell type-specific differences in HCMV immediate-early (IE) transcription are suspected to underlie differences in infection permissivity, because this first phase of viral gene expression is dependent on host cell transcription factors (for review, see Ghazal and Nelson, 1993). However, analyses of IE promoter segments in gene transfection experiments with cultured cells have largely failed to confirm this hypothesis; the major IE promoter activates high levels of transcription in most cultured cell 
types, including many that are nonpermissive for HCMV infection. We recently described a transgenic mouse model system for studying HCMV major IE promoter regulation in vivo (Koedood et al., 1995). In the present report, we have used this transgenic model to analyze cell type-specific IE promoter activity in the neonatal and adult brain. The results extend our previously reported correlation between IE promoter specificity in murine tissues and known target cell types of HCMV infection in humans, and provide strong evidence that the IE promoter is a major determinant of cellular permissivity for HCMV infection. In addition, changes in IE promoter activity in the brain during development and during experimentally induced gliosis demonstrate how differentiation cues and tissue damage may play important roles in HCMV infection permissivity and pathogenesis in vivo.

\section{MATERIALS AND METHODS}

Generation of transgenic mice. Transgenic mouse lines HCMV-1 and HCMV-2 carrying lac $Z$ genes linked to the HCMV major IE enhancer/ promoter $(-524$ to +13 segment; hereafter referred to as the IE promoter) were generated as described previously (Koedood et al., 1995).

Tissue preparation. Transgene expression in brain cryosections of transgenic (hemizygous) and nontransgenic littermates of HCMV-IE-lacZ transgenic mouse lines IICMV-1 and IICMV-2 was analyzed by $\beta$-galactosidase $(\beta$-Gal) staining and by double immunofluorescence staining using antibodies against $\beta$-Gal and various cell type-specific markers. Mice were deeply anesthetized with chloral hydrate $(400 \mathrm{mg} / \mathrm{kg}$, i.p.) and perfused through the ascending aorta with $4 \%$ paraformaldehyde in $0.15 \mathrm{M}$ phosphate buffer, $\mathrm{pH} \mathrm{7.4}$. Brains were removed immediatcly after perfusion, post-fixed in the same fixative for $3 \mathrm{hr}$, and stored overnight in $10 \%$ dimethylsulfoxide in PBS for cryoprotection (Fritschy et al., 1994). Sections $(40 \mu \mathrm{m})$ were cut from frozen blocks with a sliding microtome and collected in PBS.

$\beta$-Gal staining. Free-floating sections were washed 3 times for $5 \mathrm{~min}$ in PBS and incubated for $4 \mathrm{hr}$ at $30^{\circ} \mathrm{C}$ in $\beta$-Gal stain solution with Bluo-Gal substrate (Gibco, Gaithersburg, MD) prepared as described previously (Koedood et al., 1995). The stained sections were washed 5 min in PBS, transferred briefly through $\mathrm{dI} \mathrm{I}_{2} \mathrm{O}$, and mounted onto gelatin-coated slides, air-dried, post-fixed $5 \mathrm{~min}$ in $4 \%$ paraformaldehyde in PBS, and washed 5 min in PBS before counterstaining with neutral red and mounting coverslips out of xylene. For whole-mount staining of the leptomeninges, brains from perfused neonatal mice were bisected sagittally, washed 3 times for $20 \mathrm{~min}$ in PBS, and stained $4 \mathrm{hr}$ at $30^{\circ} \mathrm{C}$ in $\beta$-Gal stain solution. They were then washed $15 \mathrm{~min}$ in PBS and post-fixed overnight in $4 \%$ paraformaldehyde in PBS before photography. The $\beta$-Gal activity was detected primarily in cell nuclei, attributable to the fusion of a nuclear localization signal in frame with the lac $Z$ transgene used to prepare these transgenic mice.

Immunoperoxidase staining. Frec-floating sections were incubated overnight in primary antibody (rabbit anti- $\beta$-Gal Nr. 0631-0002, Cappel, West Chester, PA) diluted 1:5000 in PBS containing $2 \%$ normal scrum and $0.2 \%$ Triton $X-100$, and then processed for the avidin-biotin-peroxidase method of Hsu ct al. (1981), according to the specifications of the manufacturer (Vectastain Elite kits, Vector Laboratories, Burlingame, CA), using diaminobenzidine hydrochloride as chromogen. Stained sections were mounted on gelatin-coated slides, air-dried, dehydrated in ascending series of ethanol, and coverslipped out of xylene.

Immunofluorescence staining. Colocalization of $\beta$-Gal-positive nuclei with neuronal markers [microtubule-associated protein 2 (MAP-2) (Matus et al., 1981) and $\mathrm{GABA}$, receptor $\beta 2,3$ subunits (Richards et al., 1987)] and with astroglial markers [glial fibrillary acid protein (GFAP) (Bignami et al., 1980) and calcium-binding protcin S100) $\beta$ (Boyes et al., 1986)] were analyzed by double immunofluorescence staining. For this purpose, sections were incubated overnight with a mixture of primary antibodies (e.g., $\beta$-Gal and MAP-2) diluted in PBS containing $2 \%$ normal serum and $0.2 \%$ Triton X-100, washed three times with PBS, and incubated for $30 \mathrm{~min}$ with secondary antibodies coupled either to dichlorotriazinylaminofluorescein (1:100) or carboxymethylindocyanine (Cy3) (1: 200; Jackson Immunoresearch, West Grove, PA). Selectivity was ensured by using primary antibodies raised in different species. Controls for specificity were performed by omitting one of the primary antibodies during the overnight incubation. The sections were then mounted on gelatin-coated glass slides, air-dricd, coverslipped with buffered glycerol, and analyzed by confocal laser microscopy (Leica TCS 4D, Nussloch, Germany).

Cortical lesion. A stab lesion was made unilaterally under stereotaxic control in the frontal cortex of transgenic mice and nontransgenic control littermates. The mice were deeply anesthetized by intraperitoneal administration of ketamin $(100 \mathrm{mg} / \mathrm{kg})$ and xylacin $(16 \mathrm{mg} / \mathrm{kg}$ ) before the operation. Lesioned mice and unlesioned controls were perfused at various time points $(0,6$, and $12 \mathrm{hr}$, and 1,3 , and $6 \mathrm{~d})$, and the brains were processed for immunohistochemistry with $\beta-\mathrm{Gal}$ and GFAP antibodies as described above. All animal procedures were performed according to the Swiss animal protection laws and the principles of laboratory animal care (National Institutes of Health publ. No 85-23).

\section{RESULTS \\ Identification of brain regions and cell types with HCMV IE promoter activity}

The cell type-specific activity of the HCMV IE promoter was analyzed by $\beta$-Gal staining and immunohistochemical analysis of brain tissue from neonatal and older mice of transgenic lines HCMV-1 (Figs. 1,2) and HCMV-2 (latter not shown) carrying lac $Z$ genes driven by the IE promoter -524 to +13 segment. The qualitative similarity in IE promoter specificity in these two lines during embryogenesis has been described previously (Koedood et al., 1995). In the brain, IE pronoter activity was observed in nearly identical sites and cell types in the two transgenic lines, but, as in embryonic tissues, HCMV-1 line mice yiclded consistently stronger expression compared with $\mathrm{HCMV}-2$ line mice in almost all the sites of activity. One activity site in HCMV-1 mice that did not appear in HCMV-2 mice was the thalamus. This difference was also apparent during embryogenesis, with HCMV-1 embryos showing unique activity in the ventral midbrain/diencephalon beginning at $10.5 \mathrm{~d}$ postcoitus (Koedood et al., 1995). The otherwise high concordance between the two lines confirms that, with the exception of the thalamus, the $l a c Z$ expression patterns observed with these mice are bona fide representations of the innate specificity of this IE promoter segment in vivo.

Anti- $\beta$-Gal immunostaining of brain sections from both newborn (postnatal day 0 , or P0) (Fig. $1 A$ ) and 5-week-old HCMV-1 mice (Fig. $1 B$ ) revealed IE promoter activity in non-neuronal structures that included the leptomeninges (Fig. 1C,D), ependymal, and choroid plexus epithelia (Fig. $1 F$ ), and in several discrete neuronal populations in the forebrain, brainstem, and cerebellum (Fig. 1A,B,E). Expression in presumptive endothelial cells (Fig. $1 G$ ) was widespread in neonatal brains (Fig. $1 A, C$ ), particularly in the pia mater (Fig. $1 C, D$ ), but was less evident in sections of more mature mice (Fig. $1 B$ ).

Immunofluorescent double-labeling analysis with antibodies against $\beta$-Gal and various cell type-specific markers indicated that in most locations, nonendothelial cells with IE promoter activity were predominantly neurons rather than astrocytes (Fig. $2 A-C$ ). GFAP- or $\mathrm{S} 100 \beta$-positive astrocytes with $\beta$-Gal immunoreactivity were rarely seen (Fig. $2 D$ ), and glial cells in white matter (oligodendrocytes) were always $\beta$-Gal-negative (data not shown). The regional distribution of neurons with IE promoter activity was similar at different stages of postnatal development, but, as was also the case for endothelial cells, the proportion of positive neurons was significantly higher in newborn mice than in older mice (in Fig. 1 , compare $\mathrm{P} 0$ section in $A$ with 5 week section in $B$ ). The distribution of brain nuclei with positive neurons is summarized in Table 1 . In mice at 5 weeks of age, a prominent labeling of neurons was observed in the olfactory bulb, hippocampus CA1 and CA3 subfields, deep cortical layers, thalamus, granule cell layer and deep nuclei of the cerebellum, and several brainstem structures (Fig. 1B). The proportion of labeled neurons varied 

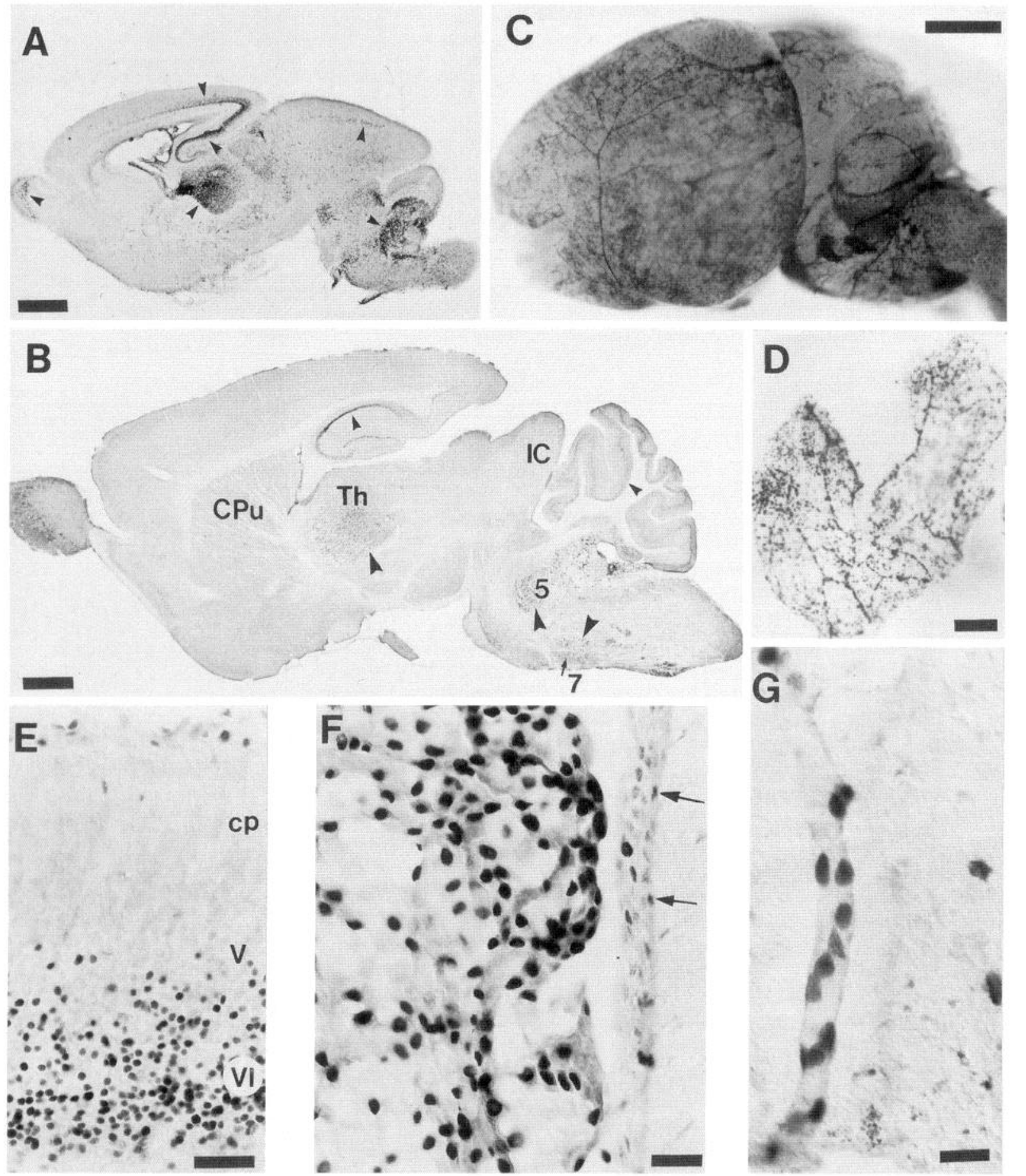

Figure 1. Distribution of cells with HCMV IE promoter activity in the brain of neonatal $(\mathrm{P} 0, A$ and $E ; \mathrm{P} 2, C$ and $D)$ and 5 week-old mice $(B, F, G)$, as visualized by $\beta$-Gal histochemical staining $(C, D, G)$ or by immunoperoxidase staining with anti- $\beta$-Gal antibodies $(A, B, E, F)$. High densities of positive nuclei are evident in specific brain regions (arrowheads in $A$ and $B$ ), especially at P0. The labeling is also prominent in the leptomeninges, as seen in a P2 whole-brain mount $(C)$ or in an isolated fragment of pia-arachnoid $(D)$, where positive nuclei are clearly associated with blood vessels. On the cellular level, positive nuclei are evident, for instance, in neurons of deep cortical layers $(E)$; in the choroid plexus and ependyma $(F$; the arrows point to weakly positive ependymal cell nuclei); and in presumptive endothelial cells lining a brain microvessel $(G)$. Abbreviations: 5 , motor nucleus of the trigeminal nerve; 7 , facial motor nucleus; $c p$, cortical plate; $C P u$, caudate-putamen; $I C$, inferior colliculus; $T h$, thalamus; $V$, cerebral cortex layer V; $V I$, cortical layer VI. Scale bars: $A-C, 1 \mathrm{~mm} ; D, 250 \mu \mathrm{m} ; E, 50 \mu \mathrm{m} ; F, 20 \mu \mathrm{m} ; G, 10 \mu \mathrm{m}$.

greatly among the various brain regions, and there was considerable regional selectivity in their distribution. Apart from the thalamus, where IE promoter activity was not independently confirmed in HCMV-2 mice, the highest proportions of labeled neurons were seen in brainstem motor nuclei and in certain sensory afferent nuclei, such as the cochlear and vestibular nuclei. In other nuclei, such as the spinal trigeminal nucleus, only a few scattered positive neurons could be detected. 

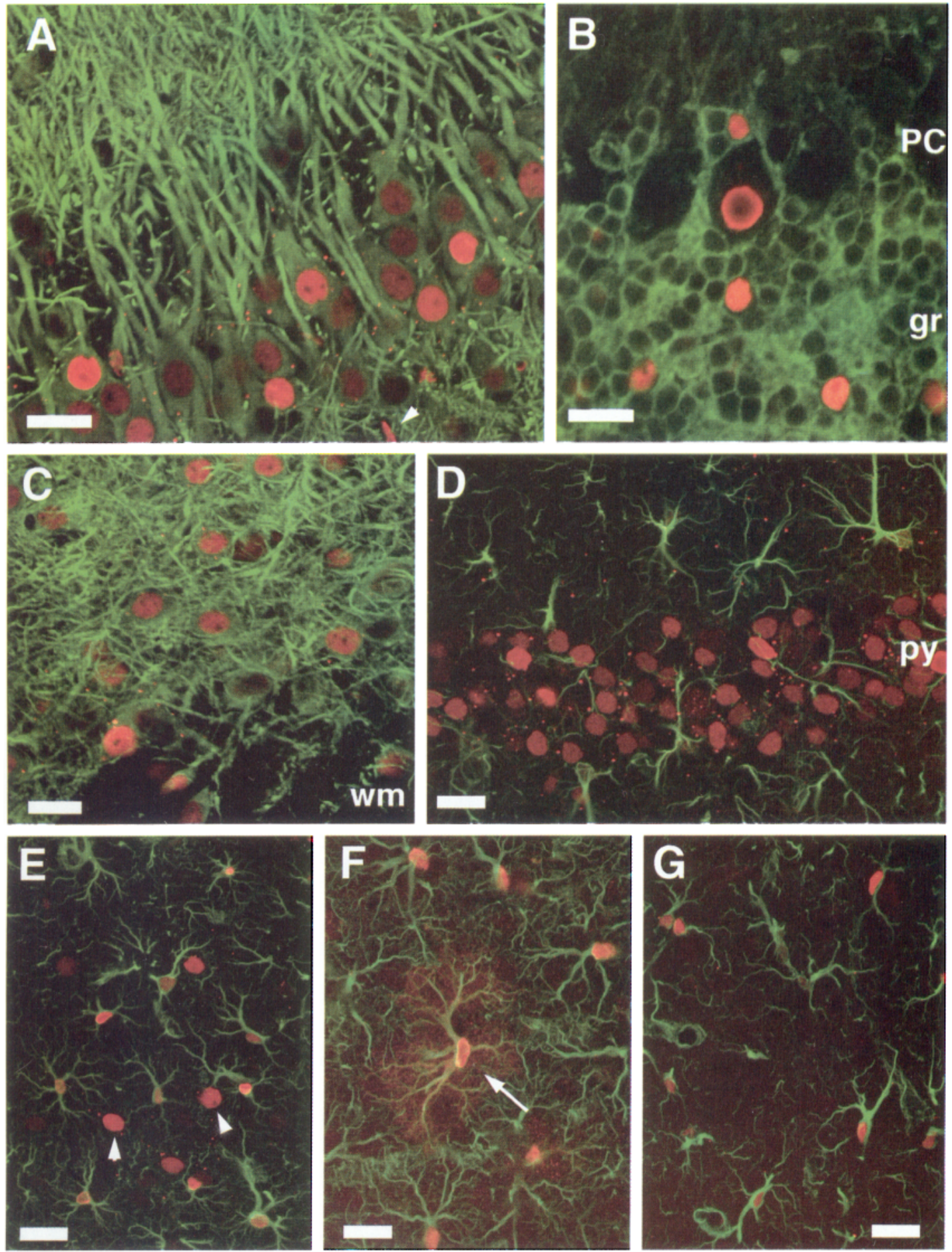

Figure 2. Video images from confocal laser microscopy illustrating cell type-specific activity of the HCMV IE promoter in selected brain regions. Antibodies against the neuron-specific markers MAP-2 $(A, C)$ and $\mathrm{GABA}_{\mathrm{A}}$ receptor $\beta 2,3$ subunits $(B)$ and against the astrocyte-specific marker GFAP $(D-G)$ were combined with $\beta$-Gal antibodies in double immunofluorescence staining experiments to identify cell types exhibiting HCMV IE promoter activity. The images corresponding to each antigen were digitized simultaneously using different filter combinations, color-coded, and superimposed. In all cases, the $\beta$-Gal immunofluorescence is shown in red, whereas the neuronal or astrocytic marker immunofluorescence is shown in green. The selective neuronal localization of HCMV IE promoter activity in normal adult brain is depicted for the hippocampus CA 3 subfield $(A)$, cerebellum $(B)$, and deep cortical layers $(C)$. The arrowhead in $A$ points to a presumptive endothelial cell nuclei (flattened profile). The lack of expression in astrocytes is illustrated for the CA1 subfield of the hippocampus $(D)$, where all $\beta$-Gal-positive nuclei are located in the pyramidal cell layer (py). By contrast, prominent HCMV IE promoter ( $\beta$-Gal-positive) activity is present in GFAP-positive reactive astrocytes $6 \mathrm{~d}$ after a stab lesion in frontal cortex, as shown in $E-G$. $E$ and $F$ depict the colocalization of $\beta$-Gal and GFAP immunoreactivity in cortical reactive astrocytes in the vicinity of the lesion $(F)$ and in the ipsilateral parietal cortex $(E)$. In certain cases, the $\beta$-Gal staining was so intense that it spread into the finest processes of the astrocyte (arrow in $F)$. Arrowheads in $E$ point to presumptive neuronal nuclei (larger, round), which are also present in the control hemisphere. $G$ depicts double-labeled astrocytes in the caudate-putamen ipsilaterally to the lesion. In both normal and lesioned brains, microglia were $\beta$-Gal-negative (data not shown). $g r$, Granule cell layer of the cerebellum; $P C$, Purkinje cell layer; $p y$, pyramidal cell layer of the hippocampus; $w m$, white matter. Scale bars, $20 \mu \mathrm{m}$. 


\begin{tabular}{|c|c|c|c|}
\hline Region & $\begin{array}{l}\text { Positive } \\
\text { neurons }\end{array}$ & Region & $\begin{array}{l}\text { Positive } \\
\text { neurons }\end{array}$ \\
\hline Olfactory bulb & & Pretectal area & - \\
\hline Glomerular layer & - & & \\
\hline Mitral cells & $*$ & Hypothalamus & - \\
\hline \multirow[t]{2}{*}{ Granule cells } & - & & \\
\hline & & Medial preoptic area & * \\
\hline \multicolumn{4}{|l|}{ Cerebral cortex } \\
\hline Layers I-IV & - & Brainstem & \\
\hline Layer V & $*$ & Tectum & - \\
\hline Layer VI, caudal & $* *$ & Red nucleus & $* *$ \\
\hline Layer VI, rostral & * & Interpeduncular nucleus & - \\
\hline Entorhinal cortex & $* *$ & Central gray & - \\
\hline \multirow[t]{2}{*}{ Subiculum } & $*$ & Dorsal raphe nucleus & $* *$ \\
\hline & & Oculomotor nucleus & $* *$ \\
\hline Hippocampal formation & & Pontine nuclei & $* * *$ \\
\hline CA1 subfield & $* * *$ & Superior olivary complex & - \\
\hline CA3 subfield & $* *$ & Trigeminal motor nucleus & $* * *$ \\
\hline \multirow[t]{2}{*}{ Dentate gyrus } & - & Facial nucleus & $* * *$ \\
\hline & & Mesencephalic trigeminal nucleus & $* * *$ \\
\hline Amygdala & & Locus coeruleus & - \\
\hline Lateral nucleus & $* *$ & Vestibular nuclei & $* * *$ \\
\hline Central nucleus & - & Cochlear nuclei & $* * *$ \\
\hline \multirow[t]{2}{*}{ Basolateral nucleus } & - & Spinal trigeminal nucleus & - \\
\hline & & Nucleus of the solitary tract & - \\
\hline Basal ganglia & & Pontine reticular formation & $* *$ \\
\hline Septal nuclei & - & Medullary reticular formation & * \\
\hline Caudate-putamen & - & Hypoglossal nucleus & $* *$ \\
\hline Pallidum & - & Inferior olivary complex & * \\
\hline Olfactory tubercle & - & & \\
\hline \multirow[t]{2}{*}{ Substantiá nigra } & - & Cerebellum & \\
\hline & & Deep nuclei & $* *$ \\
\hline Thalamus & & Granule cell layer & $*$ \\
\hline Ventroposterior nucleus & $* * *$ & Purkinje cells & - \\
\hline Lateral geniculate nucleus & $* * *$ & Molecular layer & - \\
\hline Ventrolateral nucleus & $* *$ & & \\
\hline Anterodorsal nucleus & $* * *$ & & \\
\hline Intralaminar nuclei & $*$ & & \\
\hline Mediodorsal nucleus & $*$ & & \\
\hline Reticular nucleus & - & & \\
\hline Subthalanic area & - & & \\
\hline
\end{tabular}

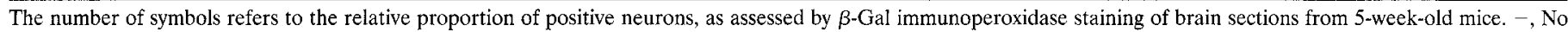
or very few positive cells; ${ }^{*},<20 \%$ positive cells; ${ }^{* *}, 20-50 \%$ positive cells; ${ }^{* * *},>50 \%$ positive cells.

Overall, the cell type specificity of the IE promoter in the mouse brain was highly consistent with known targets of HCMV infection in the human CNS (see Discussion) with one notable exception. Our analysis of normal brains failed to show IE promoter activity in astrocytes despite the fact that these cells are among the known infection targets in HCMV encephalitis in humans (Vogel, 1958; Wiley et al., 1986; Wiley and Nelson, 1988). Interestingly, a study by Poland et al. (1990) has shown that cultured astroglial cell types (including primary explants and several tumor-derived lines) vary greatly in their ability to express HCMV antigens and in their support of HCMV replication. In view of these observations, it occurred to us that astrocytes infected by IICMV in vivo may have become permissive during the course of gliosis, the reactive astrocytosis process that typically accompanies diverse neurological insults, including viral infections of the CNS. Gliosis is a common feature of HCMV infection in the brain (Haymaker et al., 1954; Wiley and Nelson, 1988; Vinters et al., 1989). Thus, we reasoned that changes in gene expression in activated astrocytes, exemplified by induction of GFAP (Eng and Ghirnikar, 1994), might lead to activation of the IE promoter and subsequent permissivity for HCMV infection.
We tested this idea experimentally in the following way. A stab lesion was made unilaterally in the frontal cortex of anesthetized transgenic mice and nontransgenic littermate controls. The mice recovered without incident and were killed for brain histology at various time points during the ensuing course of gliosis and lesion repair. Immunohistochemical analysis of brain sections was performed using antibodies against $\beta$-Gal and GFAP, a standard marker to identify reactive astrocytes during gliosis. This experiment revealed a striking and prolonged induction of IE promoter activity in the cerebral cortex of lesioned HCMV-1 transgenic mice. The induction was not evident at 0 or $6 \mathrm{hr}$ postlesion, but was first detected at 12 and $24 \mathrm{hr}$ in a few cells scattered in and around the lesion site (data not shown). The number of cells with $\beta$-Gal-positive nuclei near the lesion increased dramatically over the next $2 \mathrm{~d}$ ( $3 \mathrm{~d}$ time point; Fig. $3 A$ ). Anti-(rFAP antibody staining identified the cytoplasmic processes of reactive astrocytes distributed in a pattern similar to that of the $\beta$-Gal-positive nuclei (in Fig. 3 , compare $B$ to $A$ ). At the $6 \mathrm{~d}$ time point, numerous $\beta$-Gal-positive cells were observed around the lesion site (Fig. $3 C$ ) and, in addition, positive cells were scattered throughout the entire ipsilateral (lesioned side) cortex (Fig. 3C,E) and also in the underlying striatum (Fig. 3C,I). Interestingly, none of 


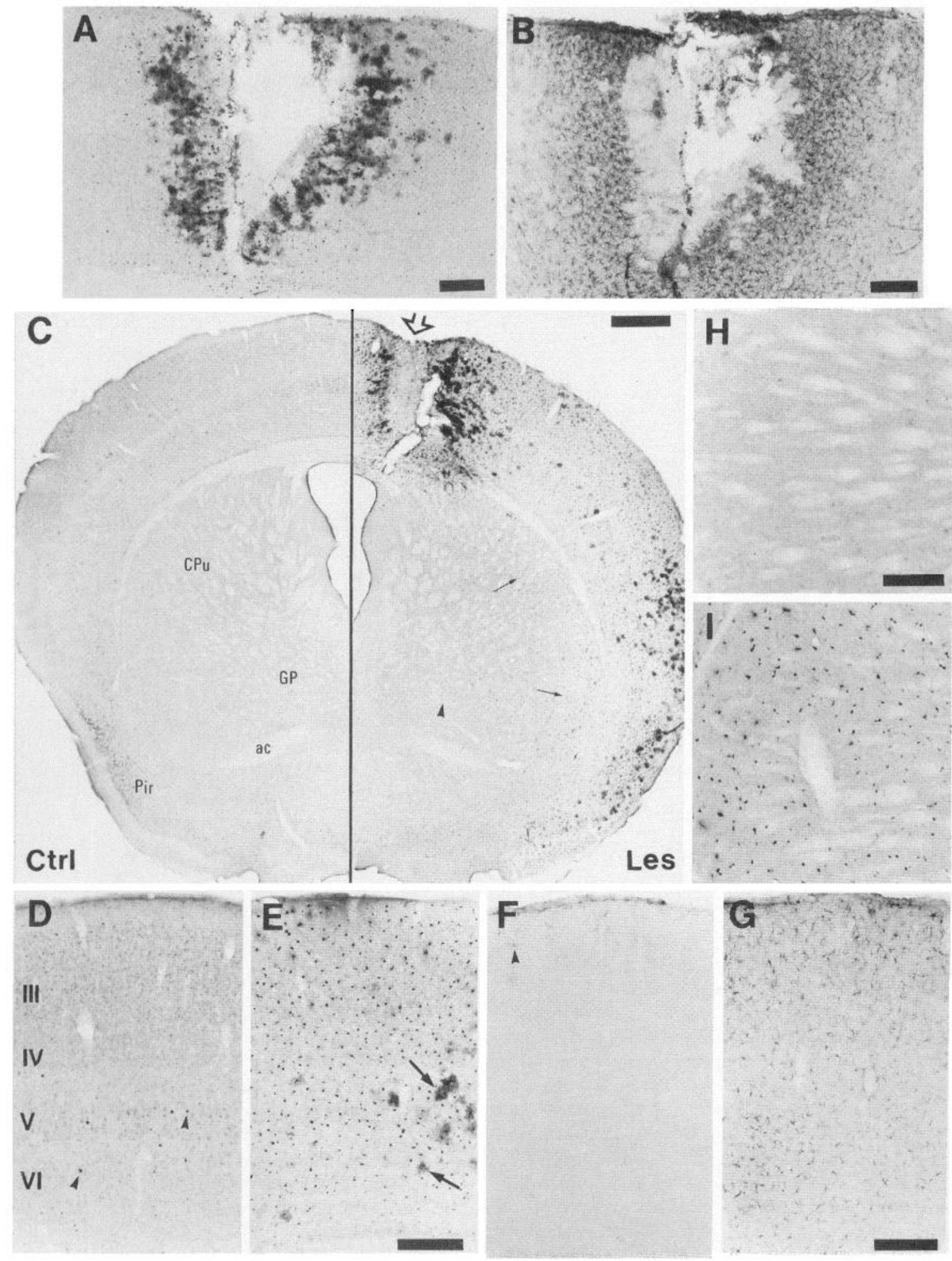

Figure 3. Induction of HCMV IE promoter activity in the ipsilateral cerebral cortex and caudate-putamen after a stab wound in the cortex. Enhanced HCMV IE promoter activity parallels the gliosis, as visualized by immunoperoxidase staining for $\beta$-Gal and GFAP, respectively. $A, B$, Lesion site after $3 \mathrm{~d}$ survival. The highly localized distribution of $\beta$-Gal-positive nuclei $(A)$ closely matches that of GFAP-positive glial cells $(B)$ around the lesion. $C$ depicts the increase in HCMV IE promoter activity seen ipsilaterally $6 \mathrm{~d}$ after the lesion [open arrow on the lesioned side (Les)] compared with the contralateral, nonlesioned side (Ctrl) of the same animal. Notice the broad distribution of $\beta$-Gal-positive nuclei throughout the ipsilateral cortex and underlying caudate-putamen ( $C P u$; arrows), but not in the globus pallidus (GP; arrowhead). The lesion-induced increase in $\beta$-Gal and GFAP staining in the ipsilateral cerebral cortex seen after $6 \mathrm{~d}$ survival is depicted in panels $E$ and $G$, respectively; the $\beta$-Gal and GFAP staining in the contralateral, control side, is shown in $D$ and $F$, respectively. Arrowheads in $D$ point to rare positive neuronal nuclei on the control side; arrows in $E$ point to dramatically enlarged astrocytes where the $\beta$-Gal immunostaining spreads into the processes (see Fig. $2 E$ for a higher magnification of such a cell). There is only very weak basal GFAP staining in cerebral cortex on the control side (arrowhead in $F$ ), whereas on the lesioned sides reactive astrocytes are distributed evenly throughout all cortical layers. $H$ and $I$ illustrate the increase in HCMV IE promoter activity in the caudate-putamen on the lesioned side $(I)$ compared with the unlesioned side $(H)$. See Figure $2 G$ for identification of these cells as astrocytes. $a c$, Anterior commissure; Pir, piriform cortex. Scale bars: $A-B$ and $D-I, 200 \mu \mathrm{m} ; C, 500 \mu \mathrm{m}$. 
the animals tested showed changes in the ipsilateral hippocampus or in the contralateral (unlesioned side) hemisphere with regard to either $\beta$-Gal- or GFAP-positive cells. Thus, at all time points tested (up to $6 \mathrm{~d}$ ), the contralateral hemisphere of the lesioned mice (Fig. $3 C, D, F, H)$ appeared much like the unlesioned controls (latter not shown).

Immunofluorescent double-labeling analysis with anti-GFAP and anti- $\beta$-Gal antibodies revealed that the majority, if not all, of the cells showing inducible IE promoter activity in the lesioned brains were reactive astrocytes, strongly positive for GFAP (Fig. $2 E-G$ ). The few $\beta$-Gal-positive nuclei present in GFAP-negative cells in these sections had the typical size and morphology of neuronal nuclei, and likely represented neurons that were already $\beta$-Gal-positive before lesioning. A similar proportion of $\beta$-Gal-positive neurons was also secn in the contralateral hemisphere and in unlesioned controls. The double-labeling analysis also revealed that reactive astrocytes were not entirely homogeneous with regard to IE promoter induction because a fraction of the GFAP-positive astrocytes remained $\beta$-Galnegative. Near the lesion $(<1 \mathrm{~mm})$, these $\beta$-Gal-negative astrocytes represented $\sim 20 \%$ of all GFAP-positive astrocytes. Their proportion increased to $\sim 35 \%$ in areas of the cortex distant from the lesion $(>3$ $\mathrm{mm})$. Finally, there was no evidence for the induction of IE pronoter activity in other cell types, notably endothelial cells or microglial cells in the lesioned brains.

\section{DISCUSSION}

In the study presented here, we have shown that the HCMV major IE promoter $(-524$ to +13 segment $)$ is active in restricted sites and cell types in brains of transgenic mice. Cell types that were competent to activate the IE promoter included some endothelial cells, ependymal cells, choroid plexus epithelia, and discrete neuron populations in the deep cortex, hippocampus, cerebellum, thalamus, brainstem, and olfactory bulb. The proportions of endothelial cells and neurons with activity were greater in neonatal than adult brains. Although the IE promoter was notably inactive in most astrocytes in the normal adult brain, it was inducible in reactive astrocyles during gliosis in response to a cortical lesion. Gliosis, an astrocytic response to diverse neurological insults, is a typical finding in HCMV encephalitis (Haymaker et al., 1954; Eng and Ghirnikar, 1994). The cell type- and differentiation status-dependent activity of the IE promoter documented here is highly consistent with known features of HCMV infection permissivity in culture and in vivo (Lathey ct al., 1990; Poland et al., 1990; Fiala et al., 1993). In autopsied brain tissue from individuals dying of fatal infection, cytomegalic cells (HCMV-infected cells that are characteristically enlarged and contain Cowdry type A viral inclusion bodies) have been noted in endothelial cells, ependymal and choroid plexus epithelia, and in astrocytes and neurons (Haymaker et al., 1954; Klatt and Shibata, 1988; Wiley and Nelson, 1988, 1993; Vinters et al., 1989; Fiala et al., 1993; Vinters and Ferreiro, 1993). Sites of infection frequently noted in congenital and adult HCMV encephalitis include leptomeningeal blood vessels, choroid plexus, and ependymal and subependymal (subventricular) regions; less frequently, infection has also been observed in the granule cell layer of the cerebellum, caudate-putamen, pallidum, thalamus, and olfactory bulb (Worth and Howard, 1950; Haymaker et al., 1954; Wiley et al., 1986; Vinters et al., 1989). Together with our previous work showing correlation between sites of IE promoter activity in transgenic mouse embryos and known target tissues of congenital HCMV infection in human fetuses (Koedood et al., 1995), the present analysis extends this correlation to specific cell types and regions in the neonatal and adult brain. The data provide strong evidence that cell type specificity of the IE promoter is conserved between humans and mice and that this promoter plays a major role in determining cellular permissivity for HCMV infection in humans.

Although it has been long suspected that the interaction between host cell transcription factors and the major IE promoter plays an important role in HCMV infection permissivity, gene transfection experiments with cultured cells have confused this issue by paradoxically suggesting that the IE promoter is highly active in most cell types. In contrast, we have observed restricted activity of the IE promoter in vivo. More importantly, the in vivo cell type specificity of the IE promoter correlates well with known targets of HCMV infection in humans. Based on this correlation, it appears that transgenic mice constitute a more relevant probative system than transfected cultured cells for studying IE promoter regulation as it pertains to HCMV infections in vivo.

Among the cell types able to activate IE promoter transcription in the brain, endothelial cells represent key targets of HCMV infection with regard to encephalopathies because they maintain the tight junction blood-brain barrier, which normally blocks entry of virus into the CNS. Infected endothelial cells have been strongly implicated as major disseminators of virus during systemic HCMV infections (Vogel, 1958; Grefte et al., 1993; Waldman et al., 1995). In AIDS patients, HCMV infection of endothelial cells is belicved to facilitate entry and dissemination of HIV in the CNS by causing a breakdown in the blood-brain barrier and attracting HIV-infected inflammatory cells (macrophages and multinucleated giant cells) into the brain (Wiley and Nelson, 1993). Thereafter, HCMV and HIV may act synergistically to cause particularly severe encephalopathies (Nelson et al., 1988; Skolnik et al., 1988; Ho et al., 1990). Histopathological analysis of HCMV-infected brain tissue suggests that HCMV can spread from the leptomeninges into underlying tissue via microvasculature to cause focal subdural damage (frequently seen in AIDS patients with HCMV encephalitis), and also can spread from the brain ventricles in a ventriculofugal manner (from ependyma into adjacent subependymal regions) (Haymaker et al., 1954; Wiley and Nelson, 1988; Vinters et al., 1989). Because a recent in vitro study suggests that efficient transmission of HCMV requires direct cell:cell contact (Waldman et al., 1995), it seems likely that ventricular spread of HCMV infection may be preceded by infection of the choroid plexus, where ventricular ependymal cells are uniquely juxtaposed to a rich bed of endothelial cells and choroid plexus epithelia.

HCMV also has been implicated in other nervous system pathologies that involve destruction of blood-nerve or blood-brain barriers, including Guillain-Barré syndrome-like polyneuropathies that have been observed in previously healthy individuals after HCMV mononucleosis (Bale, 1984; Fiala et al., 1993), and Rasmussen's encephalitis, a form of childhood epilepsy caused by autoimmune antibodies against glutamate receptors (Rogers et al., 1994; Jay et al., 1995; Twyman et al., 1995). HCMV DNA has been detected by polymerase chain reaction in brain tissue from 8 of 10 patients with Rasmussen's encephalitis (and in 0 of 5 controls with other types of encephalitis), and has been postulated to be an important cofactor by causing chronic blood-brain barrier disruption that allows leakage of antiglutamate receptor antibodies into the brain (Jay et al., 1995).

Several families of DNA-binding transcription factors, including cAMP response element binding, $\mathrm{NF} \kappa \mathrm{B} / \mathrm{rel}$, and retinoic acid receptor factors have been implicated in activation of the $\mathrm{IE}$ 
promoter in various cell types (for review, see Ghazal and Nelson, 1993). The delayed in vivo induction that we have characterized in astrocytes likely represents dependence on de novo synthesis of transcription factors or on the relatively slow decay of a repressor. Given the similarity in induction kinetics for the IE and GFAP promoters in reactive astrocytes, it is possible that the two promoters are regulated via the same signal transduction pathway(s). Relevant signaling molecules may include interleukin and TGF- $\beta$ family cytokines that are known to be released in response to stab lesioning and to have effects on transcription of the GFAP promoter (Brenner, 1994). Interestingly, we have observed that the IE promoter is activated in cortical slice cultures of the HCMVIE-lac $Z$ transgenic mice (unpublished data), indicating that experimental approaches using organ and slice cultures may be useful for studying IE promoter regulation in response to growth factors and cytokines.

In conclusion, this transgenic analysis provides compelling evidence that cell type-specific regulatory proteins that act on the IE promoter are significant determinants of HCMV infection specificity in the brain. Expansion of potential infection targets by IE promoter induction as exemplified in reactive astrocytes is likely to play an important role in progression of HCMV encephalitis and in opportunistic infection strategies used by HCMV in other tissues as well. This transgenic system should facilitate identification of cellular transcription factors that repress or activate the IE promuler in vivo and thereby affect permissivity for HCMV infection.

\section{REFERENCES}

Alford CA, Britt WJ (1990) Cytomegalovirus. In: Virology, 2nd Ed (Fields BN, Knipe M, eds), pp 1981-2010. New York: Raven.

Bale JF (1984) Human cytomegalovirus infection and disorders of the nervous system. Arch Neurol 41:310-320.

Bignami A, Dahl D, Rueger DC (1980) Glial tibrillary acidic protein (GFA) in normal neural cells and in pathological conditions. Adv Cell Neurobiol 1:285-310.

Boyes BE, Kim SU, Lee V, Sung SC (1986) Immunohistochemical colocalisation of $S 100 \beta$ and the glial fibrillary acidic protein in rat brain. Neurnscience 17:857-865.

Brenner M (1994) Structure and transcriptional regulation of the GFAP gene. Brain Pathol 4:245-257.

Eng LF, Ghirnikar RS (1994) GFAP and astrogliosis. Brain Pathol 4:229-237.

Fiala M, Graves MC, Grody WW, Vinters HV (1993) Role of cytomegalovirus infection in acquired immunodeficiency syndrome, with emphasis on neurological and ophthalmological complications. In: Molecular aspects of human cytomegalovirus diseases (Becker Y, Durai G, Huang E-S, eds), pp 128-149. Berlin: Springer.

Fritschy JM, Paysan J, Enna A, Mohler H (1994) Switch in the expression of rat $\mathrm{GABA}_{\mathrm{A}}$-receptor subtypes during postnatal development: an immunohistochemical study. J Neurosci 14:5302-5324.

Ghazal P, Nelson JA (1993) Transcription factors and viral regulatory proteins as potential mediators of human cytomegalovirus pathogenesis. In: Molecular aspects of human cytomegalovirus diseases (Becker Y, Durai G, Huang E-S, eds), pp 360-383. Berlin: Springer.

Grefte A, van der Giessen M, van Son W, The TH (1993) Circulating cytomegalovirus (CMV)-infected endothelial cells in patients with active CMV infection. J Infect Dis 167:270-277.

Haymaker W, Girdany BR, Stephens J, Lillie RD, Fetterman GH (1954) Cerebral involvement with advance periventricular calcification in generalized cytomegalic inclusion disease in the newborn. J Neuropathol Exp Neurol 13:562-586.

Ho WZ, Harouse JM, Rando RF, Gonczol E, Srinivasan A, Plotkin SA (1990) Reciprocal enhancement of gene expression and viral replication between human cytomegalovirus and human immunodeficiency virus type 1. J Gen Virol 71:97-103.

Hsu SM, Raine L, Fanger H (1981) Use of avidin-biotin-peroxidase complex $(A B C)$ in immunoperoxidase techniques: a comparison be- tween $\mathrm{ABC}$ and unlabeled antibody (PAP) procedures. J Histochem Cytochem 29:577-580.

Huang E-S, Kowalik TF (1993) The pathogenicity of human cytomegalovirus: an overview. In: Molecular aspects of human cytomegalovirus diseases (Becker Y, Durai G, Huang E-S, eds), pp 3-45. Berlin: Springer.

Jay V, Becker LE, Otsubo H, Cortez M, Hwang P, Hoffman HJ, Zielenska M (1995) Chronic encephalitis and epilepsy (Rasmussen's encephalitis): detection of cytomegalovirus and herpes simplex 1 by the polymerase chain reaction and in situ hybridization. Neurology 45:108-117.

Klatl EC, Shibata D (1988) Cytomegalovirus infection in the acquired immunodeficiency syndrome. Arch Pathol Lab Med 112:540-544.

Koedood M, Fichtel A, Meier P, Mitchell PJ (1995) Human cytomegalovirus (HCMV) immediate-early enhancer/promoter specificity during embryogenesis defines target tissues of congenital HCMV infection. J Virol 69:2194-2207.

Lathey JL, Wiley CA, Verity MA, Nelson JA (1990) Cultured human brain endothelial cells are permissive for infection by human cytomegalovirus. Virology 176:266-273.

Matus A, Bernhardt R, Hugh-Jones T (1981) High molecular weight microtubule associated protein are preferentially associated with dendritic microtubules in brain. Proc Natl Acad Sci USA 78:3013-3014.

Nelson JA, Reynolds-Kohler C, Oldstone MBA, Wiley CA (1988) HIV and HCMV coinfect brain cells in patients with AIDS. Virology $165: 286-290$

Perlman JA, Argyle C (1992) Lethal cytomegalovirus infection in preterm infants: clinical, radiological, neurological findings. Ann Neurol 31:64-68.

Poland SD, Costello P, Dekaban GA, Rice GPA (1990) Cytomegalovirus in the brain: in vitro infection of human brain-derived cells. J Infect Dis $162: 1252-1262$.

Richards JG, Schoch P, Haring P, Takacs B, Mohler H (1987) Resolving $\mathrm{GABA}_{\mathrm{A}}$ /benzodiazepine receptors: cellular and subcellular localization in the CNS with monoclonal antibodies. J Neurosci 7:1866-1886.

Rogers SW, Andrews PI, Gahring LC, Whisenand T, Cauley K, Crain B, Hughes TE, Heinemann SF, McNamara JO (1994) Autoantibodies to glutamate receptor GluR3 in Rasmussen's encephalitis. Science 265:648-651

Saigal S, Lunyk O, Larke RPB, Chernesky MA (1982) The outcome in children with congenital cytomegalovirus infection. Am J Dis Child 136:896-901.

Skolnik PR, Kosloff BR, Hirsch MS (1988) Bidirectional interactions between human immunodeficiency virus type 1 and cytomegalovirus. J Infect Dis 157:508-514.

Twyman RE, Gahring LC, Spiess J, Rogers SW (1995) Glutamate receptor antibodies activate a subset of receptors and reveal an agonist binding site. Neuron 14:755-762.

Vinters HV, Ferreiro JA (1993) Pathology of human cytomegalovirus infection. In: Molecular aspects of human cytomegalovirus diseases (Becker Y, Durai G, Huang E-S, eds), pp 46-71. Berlin: Springer.

Vinters HV, Kwok MK, Ho HW, Anders KH, Tomiyasu U, Wolfson WL, Robert F (1989) Cytomegalovirus in the nervous system of patients with the acquired immune deficiency syndrome. Brain $119: 245-268$

Vogel FS (1958) Enhanced susceptibility of proliferating endothelium to salivary gland virus under naturally occurring and experimental conditions. Am J Pathol 34:1069-1075.

Waldman WJ, Knight DA, Huang E, Sedmak D (1995) Bidirectional transmission of infectious cytomegalovirus between monocytes and vascular endothelial cells: an in vitro model. J Infect Dis 171:263-272.

Wiley CA, Nelson JA (1988) Role of human immunodeficiency virus and cytomegalovirus in AIDS encephalitis. Am J Pathol 133:73-81.

Wiley CA, Nelson JA (1993) Role of cytomegalovirus infection in neurologic abnormalities of acquired immunodeficiency syndrome. In: Molecular aspects of human cytomegalovirus diseases (Becker Y, Durai G, Huang E-S, eds), pp 119-127. Berlin: Springer.

Wiley CA, Schrier RD, Denaro FJ, Nelson JA, Lampert PW, Oldstone MBA (1986) Localization of cytomegalovirus proteins and genome during fulminant central nervous system infection in an AIDS patient. J Neuropathol Exp Neurol 25:127-139.

Worth WA, Howard HL (1950) New features of inclusion disease of infancy. Am J Pathol 26:17-35. 